\title{
Ossified Spinal Meningioma: A Case Report and a Review of the Literature
}

\author{
Mahmoud M. Taha, MD, PhD, FACS ${ }^{1}$ Ahmed Alawamry, MD ${ }^{1}$ Hesham R. Abdel-Aziz, MD² \\ ${ }^{1}$ Department of Neurosurgery, Faculty of Medicine, Zagazig \\ University, Zagazig, Egypt \\ 2 Department of Pathology, Faculty of Medicine, Zagazig University,

\begin{abstract}
Address for correspondence Ahmed Alawamry, MD, Department of Neurosurgery, Faculty of Medicine, Zagazig University,

Zagazig 44511, Egypt (e-mail: Dr_ahmedalawamry85@yahoo.com).
\end{abstract} Zagazig, Egypt

Surg J 2019;5:e137-e141.

\begin{abstract}
Keywords

- ossified meningioma

- spinal meningioma

- intradural extramedullary

Ossified spinal meningiomas are a rare form of spinal tumors. These tumors increase surgical morbidities due to their hard consistency and strong adhesion to the neural tissue and relatively narrow surgical space. Here, the authors describe the clinical findings, surgical strategies, and histological findings of a patient with an ossified meningioma. Preoperative diagnosis of these tumors can prevent surgical morbidities. Total resection can be curative with the application of meticulous microsurgical techniques.
\end{abstract}

Metaplastic meningiomas are a subtype of meningioma characterized by focal mesenchymal differentiation with osseous, cartilaginous, lipomatous, myxoid, or xanthomatous changes. ${ }^{1}$ These tumors are most commonly located at intradural extramedullary sites ( $40 \%$ of cases). ${ }^{2}$ Ossified meningiomas account for 0.7 to $5.5 \%$ of all spinal meningiomas. ${ }^{3}$ Symptoms are common, and surgical resection is a technically demanding procedure due to the hard consistency of these tumors and spatial restriction during surgery for spinal tumors. ${ }^{4}$

\section{Case Report}

A 22-year-old female presented with progressive heaviness in the lower limbs with gait disturbance, paresthesia of the lower limbs, and sphincter disturbances for approximately 5 weeks. Neurological examination revealed motor power grade of 3 for all muscle groups of the lower limbs and hypoesthesia with a sensory level below T4. Reflexes were exaggerated with positive Babinski and pathological reflexes. Radiological workup including magnetic resonance imaging (MRI) of the dorsal spine showed an intradural extramedullary spinal meningioma opposite the T4 to T5 level with hypointense signals on T1- and T2-weighted images of the tumor that indicated calcification (-Fig. 1A and B). Under general anesthesia and intraoperative neuromonitoring, the patient was positioned in the prone position and a midline-skin incision was made, followed by

received

February 2, 2019

accepted after revision

July 26, 2019 two levels of total laminectomy without compromising the facet joints. Further, a linear midline incision was made through the relatively tough dura. Early identification of tumor poles and cerebrospinal fluid (CSF) drainage allowed fine neural retraction. Total tumor excision (-Figs. 2 and 3) was performed using standard microsurgical techniques. Dural attachment was coagulated, and appropriate hemostasis and watertight dural closure were performed. The patient's neurological status improved to full motor power after postoperative 6 weeks using a rehabilitative physiotherapy protocol. Histopathological examination revealed ossified meningioma (-Fig. 4A and B).

\section{Discussion and Review of Literature}

Including this report, a total of 33 cases of ossified spinal meningioma have been published till 2019 according to PubMed (-Table 1). For this condition, female predominance has been clearly noted (female, 31 ; male, 2 ). The mean age of patients with this condition is 42.6 years, with the youngest patient being 15 years old. The tumor was located in the thoracic spine in all patients except four (cervical region, three; lumbar region, one). Further, the tumor was located posterior to the spinal cord in 18 patients.

Spinal meningiomas arise from the arachnoid villi of spinal nerve roots and are located within the intradural space in most
Copyright $\odot 2019$ by Thieme Medical Publishers, Inc., 333 Seventh Avenue, New York, NY 10001, USA. Tel: +1(212) 584-4662.
License terms

10.1055/s-0039-1697634. ISSN 2378-5128.

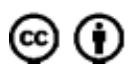



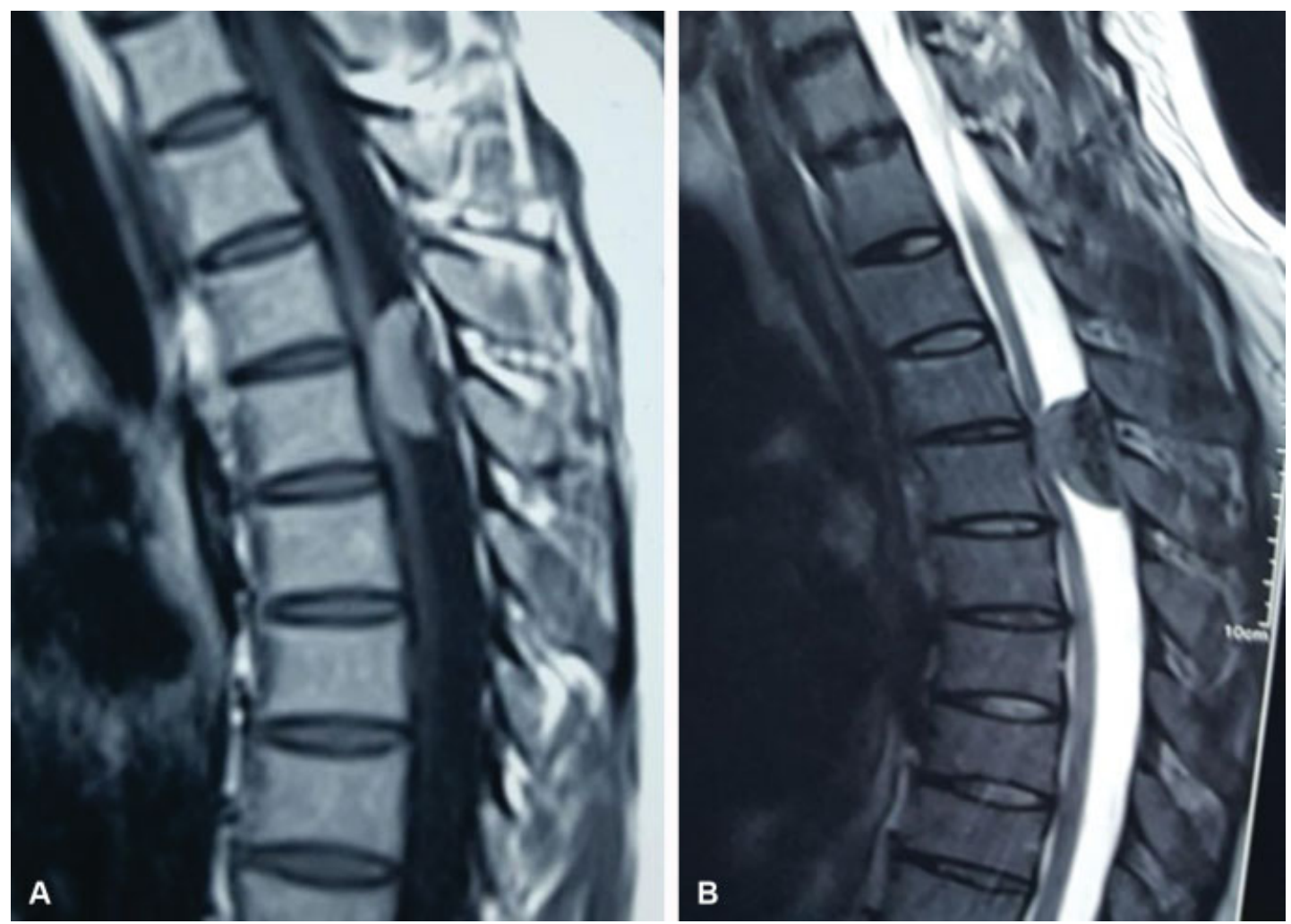

Fig. 1 (A) T1-weighted dorsal spine magnetic resonance imaging (MRI) showing spinal meningioma opposite T4-T5 with hypointense signals denoting calcifications. (B) T2-weighted dorsal spine MRI showing spinal meningioma opposite T4-T5 with hypointense signals denoting calcifications.

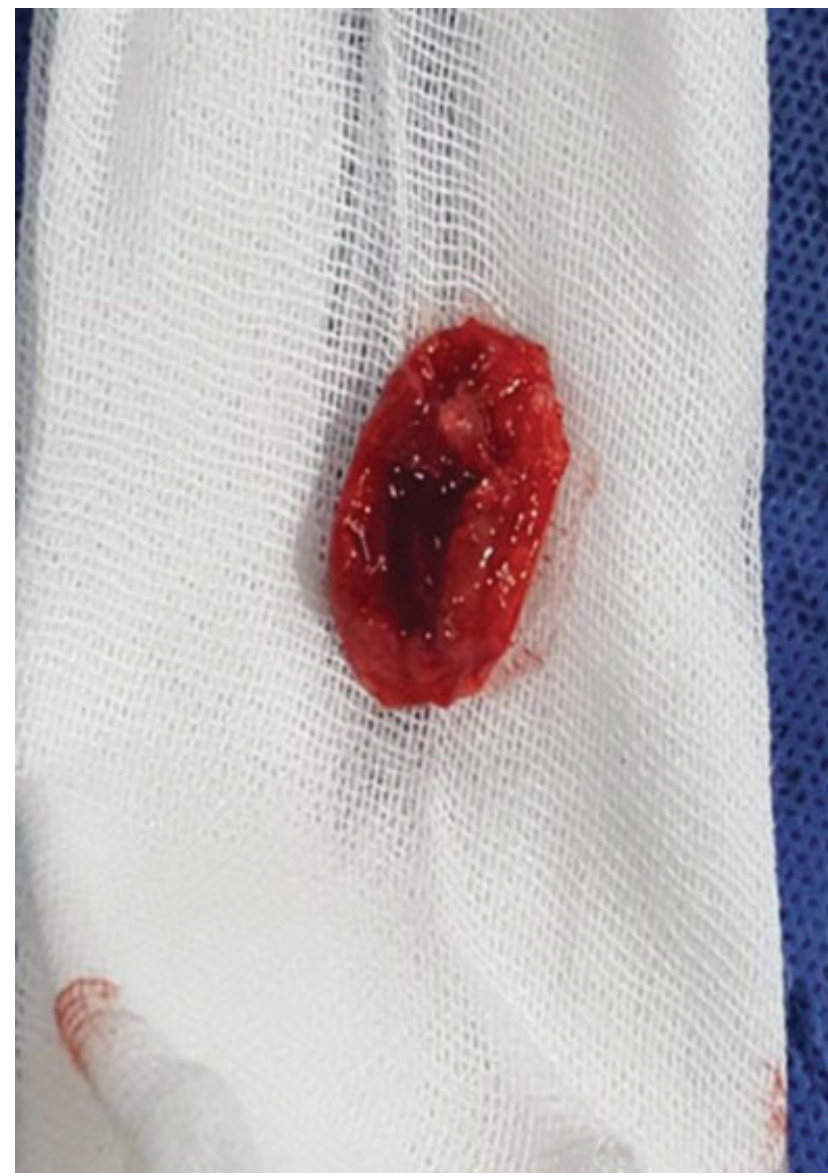

Fig. 2 Intraoperative image of excised ossified meningioma.

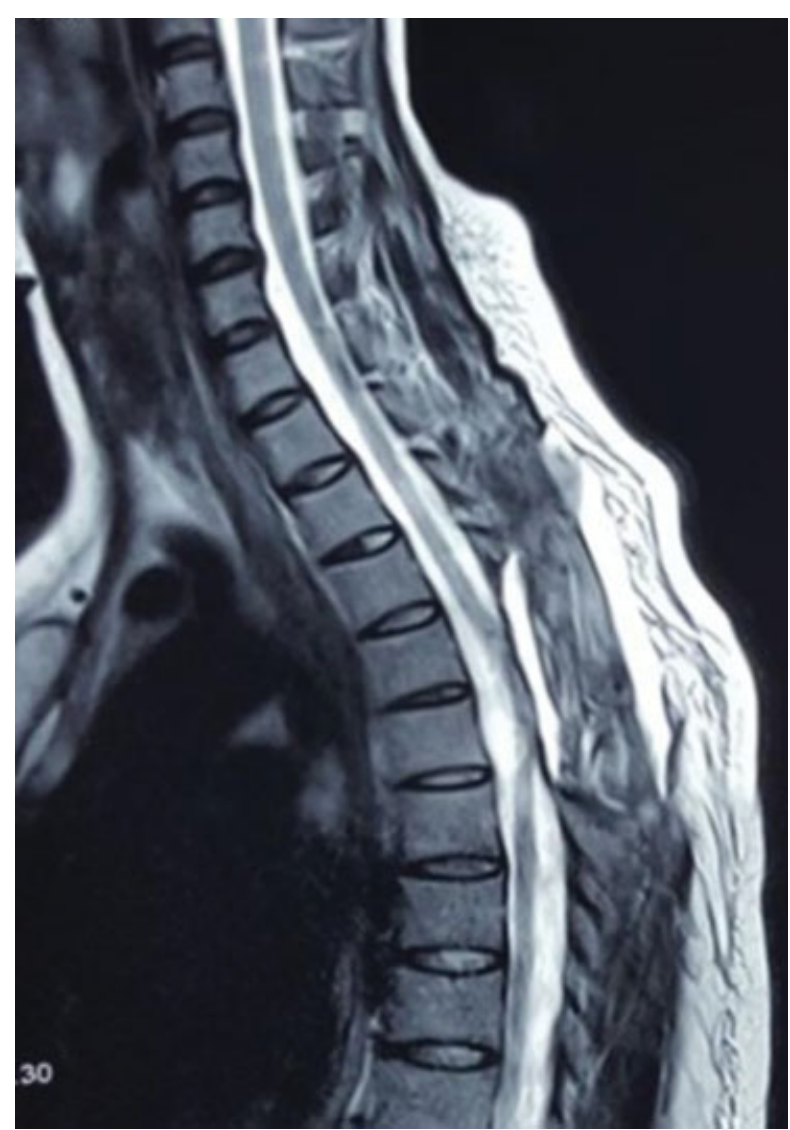

Fig. 3 Postoperative T2-weighted MRI showing complete tumor removal. MRI, magnetic resonance imaging. 

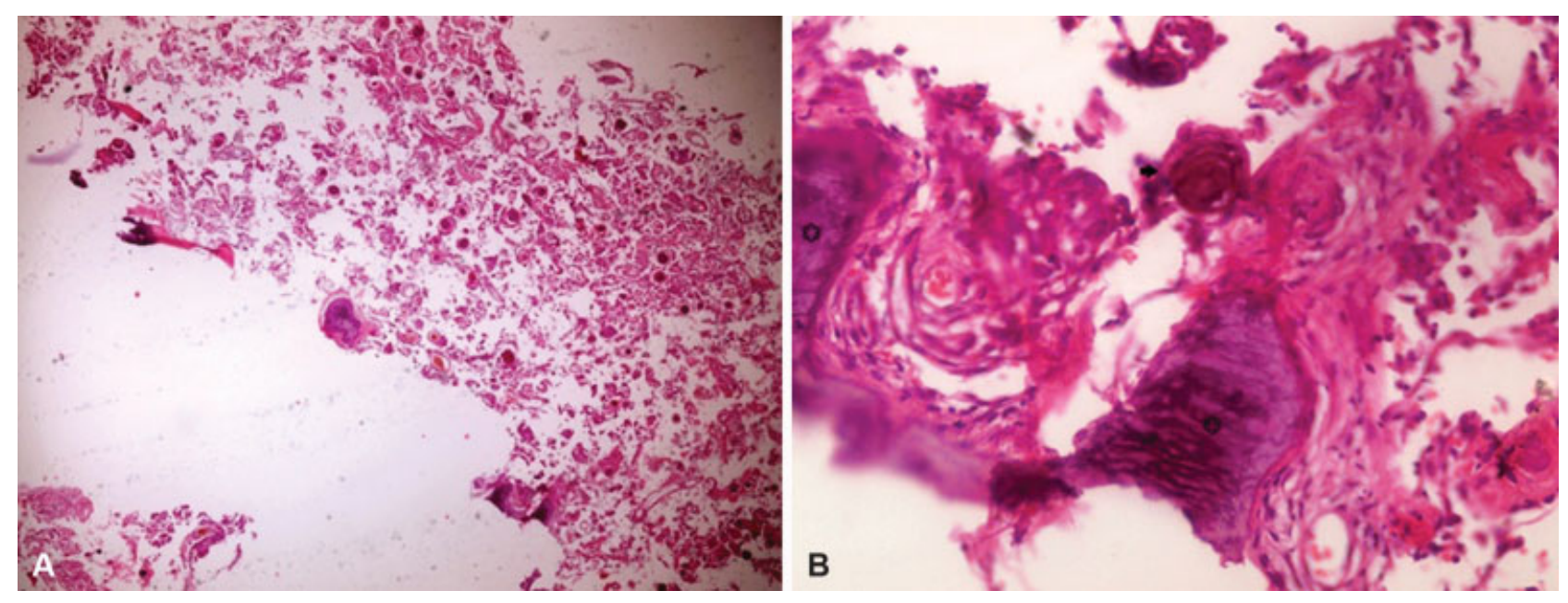

Fig. 4 (A) Photomicrograph showing meningothelial cells, calcified psammoma bodies, and scattered foci of ossification (hematoxylin and eosin [H\&E], $\times 40$ ). (B) Photomicrograph showing areas of irregular, calcified bone trabeculae (star) and calcified psammoma body (arrow; H\&E, $\times 400$ ).

Table 1 Review of ossified meningioma cases

\begin{tabular}{|c|c|c|c|c|c|}
\hline Year & Author & Number of cases & Age and sex & Location & Level \\
\hline 1928 & Rogers $^{19}$ & 1 & $16 / \mathrm{F}^{\mathrm{a}}$ & Dorsal & $\mathrm{T}^{\mathrm{c}} 9$ \\
\hline 1972 & Freidberg $^{20}$ & 1 & $69 / \mathrm{F}$ & Ventral & $\mathrm{T} 1-2$ \\
\hline 1993 & Niijima et $\mathrm{al}^{21}$ & 2 & $75 / F-75 / F$ & Dorsal, ventral & T8-9,T9-10 \\
\hline 1994 & Kitagawa et al & 2 & $60 / F-45 / F$ & Dorsal, lateral & $\mathrm{T} 7-8, \mathrm{c} 2$ \\
\hline 1996 & Nakayama et al & 1 & $74 / \mathrm{F}$ & Dorsal & T9 \\
\hline 1999 & Huang et $\mathrm{a}^{22}$ & 1 & $73 / \mathrm{F}$ & Lateral & T5 \\
\hline 2001 & Naderi et a ${ }^{23}$ & 1 & $15 / \mathrm{F}$ & Dorsal & T4 \\
\hline 2006 & Liu et $\mathrm{a}^{24}$ & 1 & $70 / \mathrm{F}$ & lateral & $\mathrm{T} 11$ \\
\hline 2009 & Hirabayashi et $\mathrm{al}^{25}$ & 1 & $82 / \mathrm{F}$ & Dorsal & L3 \\
\hline 2009 & Uchida et al & 1 & $76 / \mathrm{F}$ & Ventral & $\mathrm{T} 12$ \\
\hline 2010 & Licci et $\mathrm{al}^{26}$ & 1 & $58 / \mathrm{F}$ & Lateral & T6 \\
\hline 2013 & Chotai et $\mathrm{al}^{27}$ & 1 & $61 / \mathrm{F}$ & Dorsal & T4-T5 \\
\hline 2013 & Ju et $\mathrm{al}^{28}$ & 1 & $61 / \mathrm{F}$ & Lateral & T9-10 \\
\hline 2013 & Taneoka et $\mathrm{al}^{29}$ & 1 & $78 / \mathrm{F}$ & Dorsal & T9 \\
\hline 2014 & Yamane et a $\left.\right|^{30}$ & 1 & $61 / \mathrm{F}$ & Ventral & $\mathrm{T} 12$ \\
\hline 2014 & Chan et al $\mathrm{a}^{31}$ & 1 & $64 / \mathrm{F}$ & Dorsal & T9-10 \\
\hline 2015 & Alafaci et al & 9 & Mean age 59 years $/ 8 \mathrm{~F}-1 \mathrm{~m}^{\mathrm{b}}$ & 4 ventral, 4 dorsal, 1 lateral & 7 thoracic, 2 cervical \\
\hline 2016 & Demir et a $3^{32}$ & 1 & $26 / \mathrm{F}$ & Dorsal & T9-t11 \\
\hline 2016 & Xia et $a^{33}$ & 1 & $90 / \mathrm{M}$ & Dorsal & T10-T11 \\
\hline 2016 & Kim et $\mathrm{al}^{34}$ & 2 & $51 / \mathrm{F}-77 / \mathrm{F}$ & Dorsal, lateral & $\mathrm{T} 4, \mathrm{t} 9$ \\
\hline 2018 & Prakash et al ${ }^{35}$ & 1 & $60 / \mathrm{F}$ & Dorsal, & T7-T8 \\
\hline
\end{tabular}

${ }^{\mathrm{a}}$ Female.

bMale.

${ }^{\mathrm{T} T h o r a c i c .}$

cases. ${ }^{5}$ Except complete psammomatous transformation, the pathogenesis of ossification remains unclear; some theories suggest that meningioma ossification occurs secondary to metaplasia of arachnoid or interstitial cells on exposure to osteoblast-transforming factors such as Sox $9 .{ }^{6}$ The selection of the initial site of mineralization and mode of calcification in psammoma bodies is attributed to hydroxyapatite crystal precipitation within the bodies which result in the formation of large psammoma bodies. Then, collagen fibers surrounding the calcified bodies accumulate deposits of apatite crystals, forming larger psammoma bodies. ${ }^{7}$ In addition, estrogen deficiency is hypothesized to enhance the process of calcification in areas containing necrotic fibroblasts and increased number of collagen fibrils. ${ }^{8,9}$ Uchida et al reported that premature arachnoid cells with pluripotency differentiate into metaplastic cells and lead to bone formation. ${ }^{8}$ 
The clinical features of ossified spinal meningiomas include motor, sensory, and sphincter dysfunctions, which exhibit different phenotypes according to the tumor location and neural compression. ${ }^{10}$

Ruggeri et al observed a statistically significant relationship between postoperative neurological status and the degree of meningioma ossification wherein surgical morbidity increased with calcified and ossified tumors. ${ }^{11}$ Detection of ossification is important during preoperative planning and preparation for safe tumor resection. Although MRI is considered as the best noninvasive neuroimaging technique, it cannot detect small amounts of calcification. High-signal areas on computed tomography $(\mathrm{CT})$ are the most important radiological features for ossification detection. ${ }^{12}$

The surgical strategy for ossified meningiomas differs from that for other classical cases of meningiomas because central tumor debulking can be challenging. Using an ultrasonic surgical aspirator is helpful for hard tissue removal, including bone removal; however, it may result in neurovascular damage. This method can be safely used at the tumor periphery. Meticulous microsurgical dissection between the pia mater and tumor surface can facilitate en bloc tumor removal. ${ }^{13}$

When attempting a complete resection, wide resection of the dural attachment tends to reduce the rate of recurrence; however, dural coagulation can also be performed. ${ }^{14}$ Splitting the dura mater into inner and outer layers is a simple technique that does not require complicated duraplasty with fascia or artificial dura. ${ }^{15}$ The use of intraoperative neuromonitoring techniques to assess motor evoked potentials (MEPs) and somatosensory evoked potentials (SSEPs) helps in reducing postoperative iatrogenic neurologic deficits. ${ }^{16}$

Approximately $90 \%$ of spinal meningiomas can be surgically resected with Simpson's grade- 1 resection. The rate of recurrence during long-term follow-up reportedly ranges from 4 to $10 \%{ }^{10}$

Adjunctive radiation therapy is considered for cases requiring subtotal resection; those with recurrent meningiomas, anterior tumor location, and en plaque and calcified meningiomas; and those wherein the surgical risk is extremely high, given patients' comorbidities and tumor location. ${ }^{17,18}$

\section{Conclusion and Recommendations}

Spinal meningiomas with a hypointense signal on MRI should indicate surgeons about the possibility of calcified or ossified meningiomas. The authors recommend the use of preoperative $\mathrm{CT}$ to detect sites of ossification. Intraoperative neuromonitoring of MEPs and SSEPs, use of a wide surgical corridor with total laminectomy, wide dural opening, identification of upper and lower poles, and early CSF drainage are helpful in decreasing neural retraction, thereby facilitating safe total resection. The authors recommend dural resection or coagulation to reduce the rate of recurrence and to avoid redo surgeries.

\section{Funding}

No financial support received.
Conflict of Interest

None declared.

\section{References}

1 Kleihues P, Cavenee WK. World Health Organization Classification of Tumours, Pathology and Genetics of Tumours of the Nervous System. Lyon, France: IARC Press; 2000

2 Raza SM, Anderson WS, Eberhart CG, Wolinsky JP, Gokaslan ZL. The application of surgical cordectomy in the management of an intramedullary-extramedullary atypical meningioma: case report and literature review. JSpinal Disord Tech 2005;18(05):449-454

3 Roux FX, Nataf F, Pinaudeau M, Borne G, Devaux B, Meder JF. Intraspinal meningiomas: review of 54 cases with discussion of poor prognosis factors and modern therapeutic management. Surg Neurol 1996;46(05):458-463, discussion 463-464

4 Kitagawa M, Nakamura T, Aida T, Iwasaki Y, Abe H, Nagashima K. [Clinicopathologic analysis of ossification in spinal meningioma]. Noshuyo Byori 1994;11(01):115-119

5 Takeuchi H, Kubota T, Sato K, Hirose S. Cervical extradural meningioma with rapidly progressive myelopathy. J Clin Neurosci 2006;13(03):397-400

6 Nakayama N, Isu T, Asaoka K, et al. [Two cases of ossified spinal meningioma]. No Shinkei Geka 1996;24(04):351-355

7 Kubota T, Sato K, Yamamoto S, Hirano A. Ultrastructural study of the formation of psammoma bodies in fibroblastic meningioma. J Neurosurg 1984;60(03):512-517

8 Uchida K, Nakajima H, Yayama T, et al. Immunohistochemical findings of multiple ossified en plaque meningiomas in the thoracic spine. JClin Neurosci 2009;16(12):1660-1662

9 Yayama T, Kobayashi S, Sato R, et al. Calcium pyrophosphate crystal deposition in the ligamentum flavum of degenerated lumbar spine: histopathological and immunohistological findings. Clin Rheumatol 2008;27(05):597-604

10 Alafaci C, Grasso G, Granata F, Salpietro FM, Tomasello F. Ossified spinal meningiomas: Clinical and surgical features. Clin Neurol Neurosurg 2016;142:93-97

11 Ruggeri AG, Fazzolari B, Colistra D, Cappelletti M, Marotta N, Delfini R. Calcified Spinal Meningiomas. World Neurosurg 2017; 102:406-412

12 Lee JW, Lee IS, Choi KU, et al. CT and MRI findings of calcified spinal meningiomas: correlation with pathological findings. Skeletal Radiol 2010;39(04):345-352

13 Doita M, Harada T, Nishida K, Marui T, Kurosaka M, Yoshiya S. Recurrent calcified spinal meningioma detected by plain radiograph. Spine 2001;26(11):E249-E252

14 Klekamp J, Samii M. Surgical results for spinal meningiomas. Surg Neurol 1999;52(06):552-562

15 Saito T, Arizono T, Maeda T, Terada K, Iwamoto Y. A novel technique for surgical resection of spinal meningioma. Spine 2001;26(16):1805-1808

16 Fehlings MG, Brodke DS, Norvell DC, Dettori JR. The evidence for intraoperative neurophysiological monitoring in spine surgery: does it make a difference? Spine 2010;35(9, Suppl): S37-S46

17 Gezen F, Kahraman S, Canakci Z, Bedük A. Review of 36 cases of spinal cord meningioma. Spine 2000;25(06):727-731

18 Kufeld M, Wowra B, Muacevic A, Zausinger S, Tonn JC. Radiosurgery of spinal meningiomas and schwannomas. Technol Cancer Res Treat 2012;11(01):27-34

19 Rogers L. A spinal meningioma containing bone. Br J Surg 1928;15 (60):675-677

20 Freidberg SR. Removal of an ossified ventral thoracic meningioma Casereport. J Neurosurg 1972;37(06):728-730

21 Niijima K, Huang YP, Malis LI, Sachdev VP. Ossified spinal meningioma en plaque. Spine (Phila Pa 1976) 1993;18(15): $2340-2343$ 
22 Huang TY, Kochi M, Kuratsu J, Ushio Y. Intraspinal osteogenic meningioma:report of a case. J Formos Med Assoc 1999;98(03): 218-221

23 Naderi S, Yilmaz M, Canda T, Acar U. Ossified thoracic spinal meningioma inchildhood: a case report and review of the literature. Clin Neurol Neurosurg 2001;103(04):247-249

24 Liu CL, Lai PL, Jung SM, Liao CC. Thoracic ossified meningioma andosteoporotic burst fracture: treatment with combined vertebroplasty andlaminectomy without instrumentation: case report. J Neurosurg Spine 2006;4(03):256-259

25 Hirabayashi H, Takahashi J, Kato H, Ebara S, Takahashi H. Surgical resection without dural reconstruction of a lumbar meningioma in an elderly woman. Eur Spine J 2009;18(Suppl. 2):232-235

26 Licci S, Limiti MR, Callovini GM, et al. Ossified spinal tumour ina 58-year-old woman with increasing paraparesis. Neuropathology 2010;30(02):194-196

27 Chotai SP, Mrak RE, Mutgi SA, Medhkour A. Ossification in an extra-intradural spinal meningioma-pathologic and surgical vistas. Spine J 2013;13(12):e21-e26

$28 \mathrm{Ju} \mathrm{Cl}$, Hida K, Yamauchi T, Houkin K. Totally ossified metaplastic spinal meningioma. J Korean Neurosurg Soc 2013;54(03): 257-260
29 Taneoka A, Hayashi T, Matsuo T, et al. Ossified thoracic spinal meningioma with hematopoiesis: A case report and review of the literature. Case Rep Clin Med 2013;2(01):24-28

30 Yamane K, Tanaka M, Sugimoto Y, Ichimura K, Ozaki T. Spinal metaplasticmeningioma with osseous differentiation in the ventral thoracic spinal canal. Acta Med Okayoma 2014;68(05): 313-316

31 Chan T, Lau VW, Chau TK, Lee Y. Ossified thoracic spinal meningioma with lamellar bone formation presented with paraparesis. J Orthop Trauma Rehab 2014;18(02):106-109

32 Demir MK, Yapicier O, Toktas ZO, Akakin A, Yilmaz B, Konya D. Ossified-calcified intradural and extradural thoracic spinal meningioma with neural foraminal extension. Spine J 2016;16(01): e35-e37

33 Xia T, Tian JW. Entirely ossified subdural meningioma in thoracic vertebral canal. Spine J 2016;16(02):e11

34 Kim J, Min W, Kim J, Park KH, Mun J. Two case reports of calcified spinal meningioma and a literature review. JKorean Soc Spine Surg 2016;23(04):227-233

35 Prakash A, Mishra S, Tyagi R, Attri PC, Bhatnagar A, Kansal S. Thoracic psammomatous spinal meningioma with osseous metaplasia: A very rare case report. Asian J Neurosurg 2017;12(02): $270-272$ 